\title{
LOYALITAS KONSUMEN DALAM PENGGUNAAN JASA RUMAH DUKA (STUDI KASUS PADA RUMAH DUKA JELAMBAR)
}

\author{
Hellen Gabrellia Santoso \\ Program Studi Magister Manajemen Universitas Tarumanagara \\ santoso.hellen@gmail.com \\ Riris Loisa \\ Program Studi Magister Manajemen Universitas Tarumanagara
}

Masuk : 04-06-2020, revisi : 25-06-2020 diterima untuk diterbitkan : 25-06-2020

\begin{abstract}
This study discusses consumer loyalty in the use of funeral home services. The theory used in this research is the theory of consumer loyalty, word of mouth theory, promotion theory, and service theory. This research uses a case study method with a qualitative descriptive research approach. The data in this study were obtained from 1 staff member and 5 (five) users of funeral home services. Funeral home services are usually used by Chinese Buddhists, Confucians, Christians and Catholics. Funeral homes don't really do marketing promotions, such as price discounts, advertisements, social media activations, and so on. Initially people know and can use the funeral home services through word of mouth. In addition, the area where they live is also close to the location of the funeral home. After using a funeral home service, they are satisfied with the service provided, so they will use the same funeral home service if needed. Because of the use of more than 1 (one) time, consumers can be said to be loyal or loyal. Consumer loyalty can be seen from their willingness to give recommendations (word of mouth) of funeral homes that they use to others. The conclusion of this study, one form of consumer loyalty is in the form of word of mouth. The location and services provided are some of the considerations underlying the funeral home consumer loyalty in this study.
\end{abstract}

Keywords: Consumer Loyalty, Word of Mouth, Promotion, Service, Location, Funeral Home

\begin{abstract}
Abstrak: Penelitian ini membahas mengenai loyalitas konsumen dalam penggunaan jasa rumah duka. Teori yang digunakan dalam penelitian ini adalah teori loyalitas konsumen, teori word of mouth, teori promosi, dan teori service atau pelayanan. Penelitian ini menggunakan metode studi kasus dengan pendekatan penelitian deskriptif kualitatif. Data dalam penelitian ini diperoleh dari 1 satu orang staf dan 5 (lima) orang pengguna jasa rumah duka. Jasa rumah duka biasanya digunakan oleh masyarakat Tionghoa beragama Buddha, Konghucu, Kristen, dan Katolik. Rumah duka tidak terlalu melakukan promosi pemasaran, seperti potongan harga, memasang iklan, pengaktifan sosial media, dan lainnya. Awalnya orang mengetahui dan dapat menggunakan jasa rumah duka melalui word of mouth. Selain itu, daerah tempat tinggal mereka juga dekat dengan lokasi rumah duka. Setelah menggunakan jasa rumah duka, mereka merasa puas akan service atau pelayanan yang diberikan sehingga mereka akan menggunakan jasa rumah duka yang sama apabila membutuhkan. Karena penggunaan lebih dari 1 (satu) kali, konsumen dapat dikatakan setia atau loyal. Loyalitas konsumen dapat dilihat dari kesediaan mereka akan memberikan rekomendasi (word of mouth) rumah duka yang mereka gunakan kepada orang lain. Kesimpulan dari penelitian ini, salah satu bentuk loyalitas konsumen adalah dalam bentuk word of mouth. Lokasi dan pelayanan yang diberikan merupakan beberapa pertimbangan yang melatarbelakangi loyalitas konsumen rumah duka pada penelitian ini.
\end{abstract}

Kata Kunci: Loyalitas Konsumen, Word of Mouth, Promosi, Pelayanan, Lokasi, Rumah Duka 


\section{PENDAHULUAN}

Melayat adalah bentuk kepedulian dari tetangga, saudara, kerabat, maupun teman dari orang yang meninggal tersebut. Dalam melayat, biasanya tamu yang datang akan mengucapkan rasa turut bela sungkawa atau berduka cita kepada keluarga yang ditinggalkan beserta doa baik bagi keluarga agar selalu diberikan kekuatan. Dalam bisnisnya, rumah duka juga memberikan jasa yang baik untuk kepuasan pelanggan. Kepuasan pelanggan merupakan suatu hal yang sangat berharga demi mempertahankan keberadaan pelanggan tersebut untuk tetap berjalannya bisnis atau usaha. Selain faktor penting bagi kelangsungan hidup perusahaan, memuaskan kebutuhan konsumen dapat meningkatkan keunggulan dalam persaingan. Konsumen yang puas terhadap produk dan jasa pelayanan cenderung untuk membeli kembali produk dan menggunakan kembali jasa pada saat kebutuhan yang sama muncul kembali di kemudian hari. Uniknya bisnis rumah duka ini jika kita perhatikan secara umum program pemasarannya hanya bersifat aktual ditempat ketika seseorang mendatangi langsung tempat pemasarannya dengan kata lain orang barulah menerima tawaran ketika mereka benar-benar membutuhkan jasa atau produk yang ditawarkan dalam hal ini ada rumah duka. Oleh karena itu, peneliti tertarik untuk meneliti loyalitas konsumen dalam penggunaan jasa rumah duka. Rumusan masalah dari penelitian ini adalah bagaimana konsumen dengan setia menggunakan jasa rumah duka? Tujuannya adalah untuk mengerahui bagaimana konsumen dapat dengan setia menggunakan jasa rumah duka. Penulis mengkhususkan penelitian ini di Rumah Duka Jelambar.

\section{METODE PENELITIAN}

Penelitian ini dilakukan untuk mengetahui tentang loyalitas konsumen dalam penggunaan jasa rumah duka. Dalam penelitian ini penulis memilih metode studi kasus dengan pendekatan penelitian deskriptif kualitatif. Menurut Robert K. Yin (2013), studi kasus adalah suatu inquiry empiris yang menyelidiki fenomena dalam konteks kehidupan nyata, bilamana batas-batas antar fenomena dan konteks tak tampak dengan tegas dan dimana: multi sumber bukti dimanfaatkan. Menurut Hidayat Syah (2010), penelitian deskriptif adalah pendekatan penelitian yang digunakan untuk menemukan pengetahuan yang seluas-luasnya terhadap objek penelitian pada suatu masa tertentu. Penelitian kualitatif menurut Lexy J. Moleong (2007) adalah penelitian yang bermaksud untuk memahami fenomena tentang apa yang dialami oleh subjek penelitian misalnya perilaku, persepsi, motivasi, tindakan, dan lain-lain, secara holistik, dan dengan cara deskripsi dalam bentuk kata-kata dan bahasa, pada suatu konteks khusus yang alamiah dan dengan memanfaatkan berbagai metode alamiah. Penulis melakukan penelitian dengan mewawancarai seorang staf Rumah Duka Jelambar, tiga orang konsumen pengguna jasa Rumah Duka Jelambar, dan dua orang konsumen pengguna jasa Rumah Duka Heaven. Selain wawancara, penulis juga melakukan obersevasi langsung dan studi kepustakaan untuk pengumpulan data. Hasil wawancara tersebut akan diseleksi dan dipilih untuk mendukung penelitian penulis. Selain itu, penulis menggunakan koding agar mendapatkan hasil yang lebih rinci. Strauss dan Corbin (Emzir, 2010) menjelaskan bahwa analisis data kualitatif terdiri atas tiga jenis pengodean, yaitu pengodean tebuka (open coding), pengodean berporos (axial coding), dan pengodean selektif (selective coding). Teknik pemeriksaan keabsahan data dalam penelitian ini menggunakan triangulasi.

\section{HASIL TEMUAN DAN DISKUSI}

Loyalitas dapat diartikan sebagai suatu kesetiaan. Kesetiaan ini diambil tanpa adanya paksaan, tetapi timbul dari kesadaran diri sendiri atas kepuasan tentang suatu hal. Usaha yang dilakukan untuk menciptakan kepuasan konsumen lebih cenderung mempengaruhi sikap konsumen. Sedangkan konsep loyalitas konsumen lebih menerangkan kepada perilaku pembelinya. Menurut Hidayat (2009), word of mouth adalah salah satu bentuk loyalitas konsumen akan suatu produk atau jasa yang sudah melekat akan konsumen tersebut. Dari tiga narasumber yang penulis wawancarai meyakini bahwa mereka setia menggunakan jasa rumah 
duka tersebut karena memang banyak kerabat mereka yang menggunakan rumah duka tersebut. Lingkungan mereka banyak menggunakan jasa Rumah Duka Jelambar. Setiap datang ke acara kedukaan, seringnya mereka datang ke Rumah Duka Jelambar. Pada studi kasus ini, word of mouth dan pengalaman penggunaan berperan penting akan loyalitas konsumen. Penggunaan jasa yang berulang kali oleh para konsumen karena mereka mendapat rekomendasi dan merasakan sendiri pelayanan yang diberikan sehingga jika ada keluarga yang meninggal, mereka akan menggunakan jasa Rumah Duka Jelambar. Sama halnya apabila ada kerabat atau orang lain yang meminta rekomendasi rumah duka, atau bahkan sedang berduka sehingga tidak dapat memikirkan lagi dimana mereka akan menyewa jasa rumah duka, konsumen yang sudah pernah menggunakan jasa Rumah Duka Jelambar akan merekomendasikan ke kerabatnya.

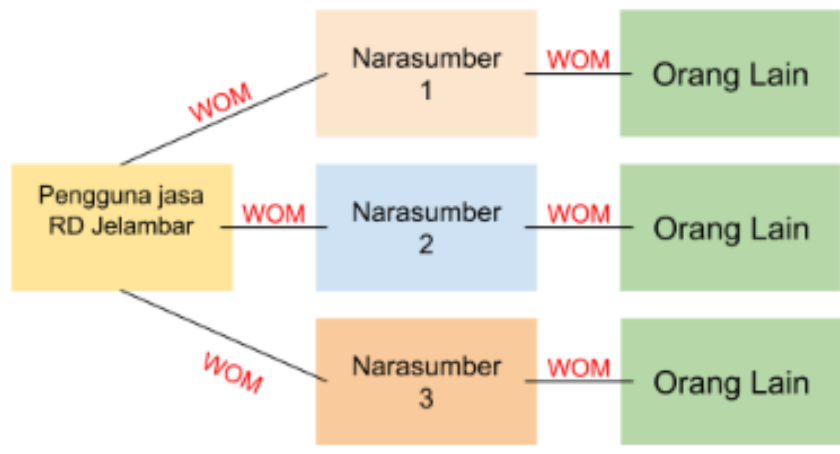

\section{Gambar 1}

Word of Mouth adalah salah satu bentuk loyalitas

Sumber: Dokumentasi Pribadi

Selain itu, lokasi rumah duka tersebut juga dekat dengan tempat tinggal mereka, lebih tepatnya masih mudah untuk dijangkau. Dengan banyaknya rekomendasi dari kerabat dan lingkungan, dengan letak yang strategis juga, Rumah Duka Jelambar menawarkan jasanya dengan harga yang dapat dibilang cukup terjangkau. Mungkin banyak orang berpikir harga yang "murah", fasilitas yang diberikan tidak kalah dengan rumah duka yang lebih mahal. Fasilitas yang diberikan cukup lengkap dan sesuai yang diperlukan. Setelah melakukan penelitian, penulis menemukan hal yang menarik. Menurut Kotler (2005), pelayanan adalah setiap tindakan atau kegiatan yang ditawarkan oleh suatu pihak kepada pihak lain, yang pada dasarnya tidak berwujud dan tidak mengakibatkan kepemilikan apapun. Produksinya dapat dikaitkan atau tidak dikaitkan pada satu produk fisik. Dari hasil penelitian, penulis menemukan bahwa pelayanan yang diberikan sudah cukup baik dan ditawarkan dengan harga yang terjangkau. Konsumen sudah percaya dengan jasa dan fasilitas yang diberikan oleh Rumah Duka Jelambar. Dari hal itu, rumah duka secara tidak langsung membuat banyak orang yang loyal atau setia akan jasa mereka.

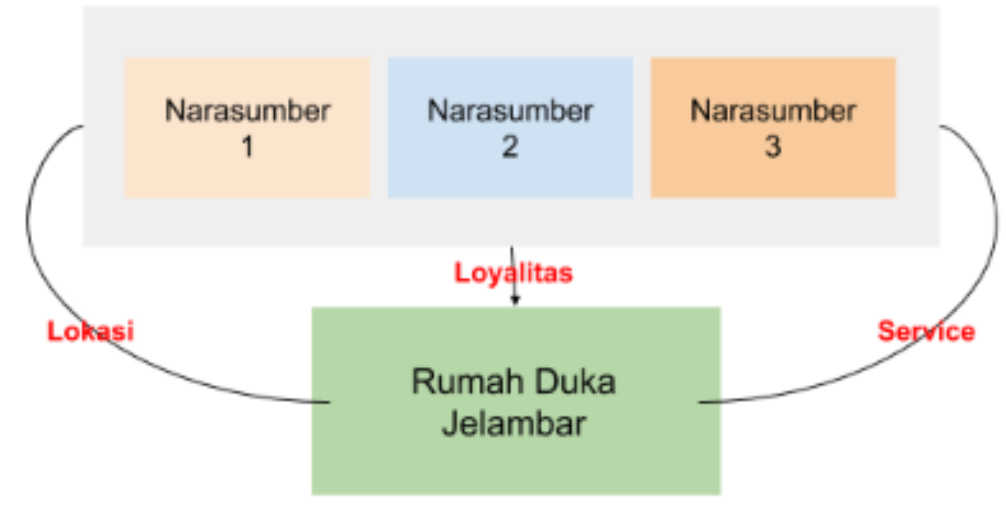

Gambar 2

Service dan Lokasi merupakan bentuk loyalitas

Sumber: Dokumentasi Pribadi 


\section{SIMPULAN}

Setelah melakukan penelitian pada tiga narasumber yang berbeda, penulis dapat menyimpulkan ada tiga hal penting yang menjadi alasan mereka menggunakan Rumah Duka Jelambar dengan loyal. Saran dari kerabat atau keluarga dekat, lokasi, dan service yang diberikan menjadi poin penting. Mereka bertiga sama mengatakan bahwa tiga hal tersebut adalah alasan bagaimana mereka dapat dengan setia menggunakan jasa Rumah Duka Jelambar. Banyak kerabat mereka yang telah menggunakan rumah duka tersebut, sehingga mereka familiar akan rumah duka tersebut. Dapat dikatakan penggunaan turun-temurun sehingga ada rasa percaya pada jasa rumah duka tersebut. Dari penelitian penulis kepada staff di rumah duka tersebut juga mengatakan hal yang sama, yaitu banyak pengguna jasa rumah duka yang turun temurun karena sudah ada rasa percaya. Sama halnya dengan konsumen pengguna jasa rumah duka lain (dalam penelitian ini, saya meneliti pengguna jasa Rumah Duka Heaven) yang mengatakan bahwa mereka menggunakan jasa Rumah Duka Heaven karena keluarganya sudah ada yang pernah menggunakan. Uniknya, jasa rumah duka tidak menggunakan iklan, namun strategi pemasaran yang digunakan adalah word of mouth, testimoni dari mulut ke mulut sehingga banyak orang mengetahui tentang rumah duka tersebut.

\section{UCAPAN TERIMA KASIH}

Peneliti berterima kasih kepada Tuhan Yesus, keluarga, Ibu Riris Loisa selaku pembimbing, seluruh staff MM Untar, teman-teman penulis yang telah mendukung melalui doa dan semangat yang tidak dapat disebutkan satu persatu.

\section{DAFTAR PUSTAKA}

Emzir. (2010). Metodologi Penelitian Kualitatif: Analisis Data. Jakarta: Raja Grafindo.

Fadila, D. \& Ridho, S. L. Z. (2013). Perilaku Konsumen. Palembang: Penerbit Citrabooks Indonesia.

Hidayat, R. (2009). Pengaruh kualitas layanan kualitas produk dan nilai nasabah terhadap kepuasan dan loyalitas nasabah Bank Mandiri. Jurnal Manajemen dan Kewirausahaan, $11(1)$.

Hidayat, S. (2010). Pengantar Umum Metodologi Penelitian Pendidikan Pendekatan Verifikatif. Pekanbaru: Suska Pres.

Kotler, P. (2005). Manajemen Pemasaran (Edisi 11). Jakarta: PT. Indeks Kelompok Gramedia. Moleong, L. J. (2007). Metodologi Penelitian Kualitatif. Bandung: Remaja Rosdakarya Offset. Yin, R. K. (2013). Studi Kasus Desain \& Metode. Jakarta: PT. Raja Grafindo Persada. 